\title{
The additional risk of malignant mesothelioma in former workers and residents of Wittenoom with benign pleural disease or asbestosis
}

\author{
A Reid, N de Klerk, G Ambrosini, N Olsen, S C Pang, A W Musk
}

Occup Environ Med 2005;62:665-669. doi: 10.1136/oem.2004.018531

See end of article for authors' affiliations

Correspondence to: Ms A Reid, Occupational and Environmental Epidemiology Group, School of Population Health, M435, University of Western Australia, Crawley, WA 6009, Australia; alisonr@ sph.uwa.edu.au

Accepted 10 April 2005

\begin{abstract}
Aims: To examine the hypothesis that people with benign pleural disease or asbestosis have an increased risk of malignant mesothelioma beyond that attributable to their degree of asbestos exposure.

Methods: Former workers and residents of the crocidolite mining and milling town of Wittenoom are participating in a cancer prevention programme $(n=1988)$. The first plain chest radiograph taken at the time of recruitment into the cancer prevention programme was read for evidence of benign pleural disease and asbestosis, using the UICC classification. Crocidolite exposure of former workers was derived from employment records and records of dust measurements performed during the operation of the asbestos mine and mill between 1943 and 1966. Based on fibre counts, exposure for former residents was determined using duration of residence and period of residence (before and after a new mill was commissioned in 1957) and interpolation from periodic hygienic measures undertaken from personal monitors between 1966 and 1992. Cox proportional hazards modelling was used to relate benign pleural disease, asbestosis, asbestos exposure, and mesothelioma.

Results: Between 1990 and 2002, there were 76 cases of mesothelioma 156 of the pleura and 20 of the peritoneum). Cases had more radiographic evidence of (all) benign pleural disease, pleural thickening, blunt/obliterated costophrenic angle, and asbestosis than non-cases. Adjusting for time since first exposure (log years), cumulative exposure (log $\mathrm{f} / \mathrm{ml}$-years), and age at the start of the programme, pleural thickening (OR=3.1, 95\% $\mathrm{Cl} 1.2$ to 7.6$)$ and asbestosis $(\mathrm{OR}=3.3,95 \% \mathrm{Cl} 1.3$ to 8.6$)$ were associated with an increased risk of peritoneal mesothelioma. There was no increased risk for pleural mesothelioma. Conclusion: The presence of benign pleural disease, in particular pleural thickening, and asbestosis appears to increase the risk of mesothelioma of the peritoneum, but not of the pleura beyond that attributable to indices of asbestos exposure in this cohort of subjects exposed to crocidolite.
\end{abstract}

B enign pleural disease (discrete plaques and pleural calcification, diffuse pleural thickening with blunt or obliterated costophrenic angles and thickening of the interlobar fissure) and asbestosis (diffuse interstitial pulmonary fibrosis) are common radiographic observations in people with occupational and environmental exposure to asbestos. ${ }^{1}$ It is not clear whether the presence of benign pleural disease or asbestosis are associated with the subsequent development of malignant mesothelioma beyond the risk attributable to the degree and timing of the asbestos exposure which has caused the benign asbestos related disease.

Several studies have reported an association between the presence of benign pleural disease or asbestosis and an increased risk of malignant mesothelioma, ${ }^{1-3}$ while Koskinen and colleagues ${ }^{4}$ found that asbestos exposed people with radiographic evidence of pleural plaques had a reduced risk of mesothelioma, compared to those without pleural plaques. However these studies could not allow for the effect of degree and duration of exposure or time since exposure or even type of exposure, indices that are known to be strong determinants of mesothelioma risk.

Knowledge about whether these conditions independently predict mesothelioma is important because it may provide insight into the biological mechanisms of mesothelioma. In addition it would lessen the uncertainty about the prognosis of developing mesothelioma in persons who have asbestos related benign pleural disease or asbestosis.

Crocidolite (blue asbestos) was mined at Wittenoom Gorge, a remote town in the Pilbara region of Western
Australia by the Australian Blue Asbestos Company between 1943 and 1966. During that time 6493 men and 415 women were employed in either the mining or milling process, ${ }^{56}$ and a further 4890 are documented to have lived and worked nearby in the township. ${ }^{7}$ We have been maintaining follow up on cohorts of former workers and residents of Wittenoom since 1975, to document the epidemiology of asbestos related diseases including asbestosis, malignant mesothelioma, and lung cancer. ${ }^{89}$

The aim of this study was to determine whether benign pleural disease and asbestosis are associated with an increased risk of malignant mesothelioma beyond that attributable to the degree and timing of the asbestos exposure. We studied the risk of mesothelioma among former Wittenoom workers and residents in whom measures of intensity and duration of crocidolite exposure are known. All subjects were participating in a cancer prevention programme. ${ }^{10}$

\section{METHODS}

\section{Exposure assessment}

Dust concentrations in the mine and mill were measured periodically between 1948 and 1966 using a konimeter, and a survey of fibre counts was performed across the industry in 1966. These measurements and employment records from the Australian Blue Asbestos Company, were used to calculate cumulative asbestos exposure for all former workers in fibreyears per ml, by adding over all their jobs the product of their estimated fibre concentration and the length of the time 
Table 1 Characteristics of pleural and peritoneal cases and non-cases

\begin{tabular}{|c|c|c|c|c|c|}
\hline & $\begin{array}{l}\text { Pleural } \\
(n=56)\end{array}$ & $\begin{array}{l}\text { Peritoneal } \\
(n=20)\end{array}$ & $\begin{array}{l}\text { Non-cases } \\
(\mathrm{n}=1912)\end{array}$ & $\begin{array}{l}\text { Total } \\
(n=1988)\end{array}$ & p value* \\
\hline & Mean (SD) & Mean (SD) & Mean (SD) & Mean (SD) & \\
\hline Age at start of study & $59(10)$ & $58(7)$ & $52(12)$ & $52(12)$ & $<0.001$ \\
\hline Age at first exposure (years) & $26(9)$ & $24(5)$ & $21(11)$ & $21(11)$ & $<0.001$ \\
\hline \multirow[t]{2}{*}{ Time since first exposed (years) } & $33(5)$ & $34(3)$ & $31(6)$ & $31(6)$ & 0.0036 \\
\hline & Mean (IQR) & Mean (IQR) & Mean (IQR) & Mean (IQR) & \\
\hline Duration of exposure (days)† & $360(134-976)$ & 585 (383-1037) & $282(103-852)$ & $286(106-868)$ & 0.0318 \\
\hline Intensity of exposure $(\mathrm{f} / \mathrm{ml}) \dagger$ & $13(3-40)$ & $24(11-96)$ & $6(2-20)$ & $6(2-20)$ & $<0.001$ \\
\hline \multirow[t]{2}{*}{ Cumulative exposure (f/ml-year) $\dagger$} & $13(6-29)$ & $38(16-135)$ & $5(2-13)$ & $5(2-14)$ & $<0.001$ \\
\hline & n (\%) & n (\%) & n (\%) & n (\%) & \\
\hline \multicolumn{6}{|l|}{ Sex } \\
\hline Male & 49 (88) & $20(100)$ & $1,383(72)$ & $1452(73)$ & $<0.001$ \\
\hline Female & $7(9)$ & 0 & $529(28)$ & $536(27)$ & \\
\hline \multicolumn{6}{|l|}{ Smoking status } \\
\hline Never & $16(29)$ & $2(10)$ & 515 (27) & $533(27)$ & 0.212 \\
\hline Past & 31 (55) & $16(80)$ & $996(52)$ & $1043(52)$ & \\
\hline Current & $9(16)$ & $2(10)$ & 401 (21) & $412(21)$ & \\
\hline \multicolumn{6}{|l|}{ Status at Wittenoom } \\
\hline ABA worker & 42 & 18 & 1136 & 1196 & $<0.001$ \\
\hline Resident & 14 & 2 & 776 & 792 & \\
\hline
\end{tabular}

spent in the job. ${ }^{5}$ Based on fibre counts collected periodically by the health Department of Western Australia until 1992 former residents of the township of Wittenoom not working directly with asbestos were assigned an intensity of exposure of $1.0 \mathrm{f} / \mathrm{ml}$ from 1943 to 1957 (when a new mill was commissioned and the town was moved), and then $0.5 \mathrm{f} / \mathrm{ml}$ between 1958 and 1966 when mining operations ceased. ${ }^{11}$ Since then, interpolation between periodic hygiene surveys using personal monitors assigned exposures from 0.5 fibres (>5 microns long) per millilitre of air $(\mathrm{f} / \mathrm{ml})$, in 1966 to $0.010 \mathrm{f} / \mathrm{ml}$ in 1992. Duration of residence was determined by questionnaire and/or from dates of residence of an asbestos worker (if the resident was related to an asbestos worker and lived at Wittenoom with him/her), or those dates found in various sources when the cohort was established (school, hospital, police or church records, Pilbara electoral roll). Cumulative exposure (fibre-years per $\mathrm{ml}$ ) was calculated from the intensity and duration of exposure. ${ }^{72}$ These estimates have been shown to agree with lung fibre burden measurements. ${ }^{13}$

\section{Cancer prevention programme}

Because of the projected incidence of mesothelioma in the workforce $^{14} 1^{15}$ all surviving members of the workers' cohort who could be contacted in early 1990 were invited to take part in a cancer prevention programme to examine the efficacy of beta carotene (synthetic all-trans) and retinol (retinyl palmitate) supplements in reducing the risk of malignant mesothelioma, lung cancer, and other cancers. ${ }^{10}$ Former Wittenoom residents and other workers with a minimum of three months occupational exposure were subsequently invited to join the programme. Subjects were randomly assigned to take either $30 \mathrm{mg}$ synthetic all-trans beta carotene or 25000 IU retinol daily except former Wittenoom residents, women of child bearing age, and subjects with abnormal liver function, who were randomised to either $0.75 \mathrm{mg}$ or $30 \mathrm{mg}$ of beta carotene daily. ${ }^{10}$ Enrolment commenced in July 1990 and participants have progressively joined since, most in the first year. Results after five years showed that the mesothelioma rate was lower in those assigned to retinol, but there was no effect associated with taking beta carotene. ${ }^{16}$ After this result and the results of overseas trials finding increased rates of lung cancer among smokers taking similar doses of synthetic beta carotene, ${ }^{17} 18$ supplementation with beta carotene was ceased in 1997, and thereafter, all participants were assigned to $25000 \mathrm{IU}$ of retinol/day only, except women of child bearing age and participants with abnormal liver function, who were offered 5000 IU of retinol daily.

\section{Chest radiographs}

Classification of benign pleural disease (discrete plaques and pleural calcification, diffuse pleural thickening with blunt or obliterated costophrenic angles, and thickening of the interlobar fissure) in accordance with the UICC/ILO classification $^{19}$ was undertaken on the standard posterior/anterior plain chest radiograph taken at the first visit of participants who joined the programme before 1997 ( $\mathrm{n}=1988)$. Asbestosis was defined as the profusion of small irregular opacities $\geqslant 1 / 0$ in $\geqslant 1$ zone bilaterally. All films were read in duplicate or triplicate by trained and experienced readers. Analysis was done using one reader. This reader was chosen as the one who, when three readers were available, agreed most closely with the median reading.

\section{Case ascertainment}

Incident cases of malignant mesothelioma were determined from the Western Australian Cancer Registry (including the Western Australian Mesothelioma Registry) to September 2002 and the Australian Mesothelioma Registry and National Cancer Statistics Clearing House to September 2000. Incident cancers were matched to our cohort using date of birth, surname, first name, middle name, address, and previous name (if any).

Participants have been followed up actively from attendance at the clinic each year and passively through death and cancer registries. For this study, subjects were censored at their date of diagnosis of mesothelioma, their date of death, or September 2000 (for non-Western Australian residents) or September 2002 (for Western Australian residents), whichever was earliest. Subjects not known to be dead or diagnosed with malignant mesothelioma were assumed alive.

Ethics approval was obtained from the Human Research Ethics Committee of the University of Western Australia. 
Table 2 Frequency of pleural disease among pleural and peritoneal cases and non-cases

\begin{tabular}{lclllr}
\hline & $\begin{array}{l}\text { Pleural } \\
\mathbf{n}(\%)\end{array}$ & $\begin{array}{l}\text { Peritoneal } \\
\mathbf{n}(\%)\end{array}$ & $\begin{array}{l}\text { Non-cases } \\
\mathbf{n}(\%)\end{array}$ & $\begin{array}{l}\text { Total } \\
\mathbf{n}(\%)\end{array}$ & p value* $^{*}$ \\
\hline Benign pleural disease (all) & $17(30)$ & $10(50)$ & $332(17)$ & $359(18)$ & $<0.001$ \\
Blunt/obliterated costophrenic angle & $4(7)$ & $4(20)$ & $98(5)$ & $106(5)$ & 0.040 \\
Diffuse pleural thickening & $12(21)$ & $9(45)$ & $225(12)$ & $246(12)$ & $<0.001$ \\
Calcified plaques & $3(5)$ & $2(10)$ & $94(5)$ & $99(5)$ & 0.513 \\
Thickening of interlobar fissure & $4(7)$ & $2(10)$ & $45(2)$ & $49(2)$ & 0.046 \\
Asbestosis & $8(14)$ & $10(50)$ & $223(12)$ & $241(12)$ & 0.002 \\
\hline *All cases $v$ non-cases. & & & & \\
\hline
\end{tabular}

\section{Statistical analysis}

Asbestos exposure variables were strongly skewed and so were transformed to their natural logs. Cox proportional hazards modelling was used to relate asbestos exposure (time since first exposure and cumulative exposure), asbestosis, and benign pleural disease to malignant mesothelioma. All analyses were undertaken using Stata 8.0. ${ }^{20}$

\section{RESULTS}

Between 1990 and 2002 there were 76 cases of malignant mesothelioma ( 69 male and 7 female). Fifty six of the cases were pleural and 20 were peritoneal (table 1). Cases were more likely to show radiographic evidence of diffuse pleural thickening, blunted or obliterated costophrenic angle, and asbestosis than non-cases (table 2).

The relative risks for mesothelioma unadjusted for asbestos exposure showed that blunt/obliterated costophrenic angles, diffuse pleural thickening, and asbestosis were associated with an increased risk of malignant peritoneal mesothelioma after adjusting for age at the start of the study only (table 3). None of the benign pleural diseases or asbestosis were associated with an increased risk of malignant pleural mesothelioma.

Adjusting for asbestos exposure (time since first exposure and cumulative exposure) attenuated the risk of peritoneal mesothelioma associated with (all) benign pleural disease and blunt/obliterated costophrenic angle. However, pleural thickening and asbestosis remained associated with an increased risk of peritoneal mesothelioma after adjusting for asbestos exposure. There was no increased risk of pleural mesothelioma associated with any of the benign pleural diseases or asbestosis after adjusting for asbestos exposure (table 3). The interaction between cumulative exposure and benign pleural disease and cumulative exposure and asbestosis was not statistically significant, for either mesothelioma type, suggesting that the slope of the dose-response relation between those with and without benign pleural disease and those with and without asbestosis was not different. When pleural thickening $(\mathrm{OR}=2.27,95 \% \mathrm{CI} 0.85$ to 6.07$)$ and asbestosis ( $\mathrm{OR}=2.49,95 \% \mathrm{CI} 0.90$ to 6.91 ) were included in the same model the association with malignant peritoneal mesothelioma remained high but not significantly so.

\section{DISCUSSION}

Using a unique cohort with known levels and timing of crocidolite exposure this study has shown that both the presence of diffuse pleural thickening and asbestosis are associated with increased risks of malignant mesothelioma of the peritoneum beyond the risk calculated to be associated with the degree of asbestos exposure. This increased risk was not observed for malignant mesothelioma of the pleura. The lack of an interaction between cumulative asbestos exposure and benign pleural disease and cumulative asbestos exposure and asbestosis indicated that there was no difference in the slope of the dose-response relation between those with or without benign pleural disease and those with or without asbestosis.

Twenty six per cent of cases in this cohort had malignant peritoneal mesothelioma. Cases of malignant peritoneal mesothelioma have been more common than malignant pleural mesothelioma in workers in some factories rather than asbestos mining. ${ }^{21-23}$ In the Wittenoom cohorts, cases of malignant peritoneal mesothelioma had a greater cumulative exposure to crocidolite than had cases of pleural mesothelioma. Similar findings have been reported by Browne and Smither among workers using asbestos in manufacturing and insulation, ${ }^{23}$ while Leigh et al reported that lung asbestos fibre content was associated with tumour site and higher lung fibre content was associated with peritoneal mesotheliomas. ${ }^{24}$ In the Wittenoom worker studies $14 \%$ of cases of malignant mesothelioma have been peritoneal in origin ${ }^{25}$ and in the residents' studies 3\% of cases of mesothelioma have been peritoneal in origin. In our cohort, the risk of peritoneal mesothelioma was increased in persons with diffuse pleural thickening or asbestosis. Browne and Smither found a higher proportion of peritoneal cases $(28 \%)$ had ante-mortem asbestosis than had pleural cases $(22 \%){ }^{23}$ Retrograde lymph drainage from the pleural to the peritoneal cavity resulting from interstitial pulmonary fibrosis has been suggested as one possible biological mechanism to explain the association

Table 3 Relative risk of pleural $(n=56)$ or peritoneal $(n=20)$ mesothelioma and radiographic evidence of benign pleural disease and asbestosis

\begin{tabular}{|c|c|c|c|c|}
\hline & \multicolumn{2}{|l|}{ Unadjusted* } & \multicolumn{2}{|l|}{ Adjusted† } \\
\hline & $\begin{array}{l}\text { Pleural MM } \\
\text { OR }(95 \% \mathrm{Cl})\end{array}$ & $\begin{array}{l}\text { Peritoneal MM } \\
\text { OR }(95 \% \mathrm{CI})\end{array}$ & $\begin{array}{l}\text { Pleural MM } \\
\text { OR }(95 \% \mathrm{Cl})\end{array}$ & $\begin{array}{l}\text { Peritoneal MM } \\
\text { OR }(95 \% \mathrm{Cl})\end{array}$ \\
\hline $\begin{array}{l}\text { Benign pleural disease (all) } \\
\text { Blunt/obliterated costophrenic angle } \\
\text { Diffuse pleural thickening } \\
\text { Calcified plaques } \\
\text { Thickening of interlobar fissure } \\
\text { Asbestosis }\end{array}$ & $\begin{array}{l}1.47(0.81 \text { to } 2.67) \\
1.10(0.39 \text { to } 3.06) \\
1.47(0.76 \text { to } 2.84) \\
0.75(0.23 \text { to } 2.43) \\
1.84(0.57 \text { to } 5.92) \\
0.93(0.43 \text { to } 1.09)\end{array}$ & $\begin{array}{l}3.97(1.55 \text { to } 10.2) \\
3.96(1.28 \text { to } 12.2) \\
5.06(1.99 \text { to } 12.9) \\
1.55(0.35 \text { to } 6.86) \\
1.76(0.23 \text { to } 13.2) \\
6.67(2.65 \text { to } 16.8)\end{array}$ & $\begin{array}{l}1.12(0.61 \text { to } 2.07) \\
0.82(0.29 \text { to } 2.32) \\
1.11(0.56 \text { to } 2.20) \\
0.67(0.21 \text { to } 2.17) \\
1.47(0.45 \text { to } 4.75) \\
0.68(0.31 \text { to } 1.49)\end{array}$ & $\begin{array}{l}2.22(0.87 \text { to } 5.68) \\
1.84(0.58 \text { to } 5.86) \\
3.05(1.22 \text { to } 7.62) \\
1.15(0.27 \text { to } 5.01) \\
1.02(0.13 \text { to } 7.67) \\
3.29(1.26 \text { to } 8.59)\end{array}$ \\
\hline
\end{tabular}

*Adjusted for age at start of the programme.

†Adjusted for age at start of programme, time since first exposure (log years), and cumulative exposure (log $\mathrm{f} / \mathrm{ml}$-year). 


\section{Main messages}

- Peritoneal mesothelioma is associated with heavier asbestos exposure.

- Benign pleural disease is dose related.

- Diffuse pleural thickening and asbestosis are associated with increased risks of malignant peritoneal mesothelioma beyond the risk calculated to be associated with the degree of asbestos exposure.

- This increased risk was not observed for malignant mesothelioma of the pleura.

between asbestosis and peritoneal mesothelioma. ${ }^{23}$ If the asbestos exposure of cases of peritoneal mesothelioma is higher than cases of pleural mesothelioma, this suggests that the crocidolite fibres are less likely to reach the peritoneal cavity than the pleural cavity, if both mesothelial surfaces are equally susceptible.

The unique strength of the present study in comparison to others that have examined this issue ${ }^{1326}$ is the availability of quantitative asbestos exposure data on all subjects in the cohorts calculated from the time they either worked in the mine or mill or were residents of Wittenoom. This information has allowed us to take into account the exposure levels of subjects with benign pleural disease when assessing their risk of malignant mesothelioma. Studies that have examined this topic without quantitative asbestos exposure information have found varying results. Based on nine cases of mesothelioma, the incidence of mesothelioma (SIR 11.25, $95 \%$ CI 5.1 to 21.4 ) was raised in subjects with pleural plaques compared to the Swedish male population after a mean time since first exposure of 48 years. ${ }^{1}$ Karjalainen et al found that the incidence of mesothelioma was raised in subjects $(\mathrm{n}=4)$ with benign pleural disease (SIR 5.5, 95\% CI 1.5 to 14$)$, and in subjects $(\mathrm{n}=9)$ with asbestosis (SIR 31.6, $95 \%$ CI 14.4 to 60$){ }^{3}$ Cvitanovic et al found that subjects with benign pleural disease or asbestosis and/or progressive benign pleural disease or asbestosis were more likely to have malignant mesothelioma than subjects without radiographic evidence of benign pleural disease or asbestosis. ${ }^{26}$ In contrast, Koskinen et al examining 13 cases of mesothelioma (four with plaques, none with asbestosis), did not find an increased risk of mesothelioma (SIR 1.19, 95\% CI 0.32 to 3.05 ) in subjects with pleural plaques. ${ }^{4}$ The models we presented with risk of mesothelioma unadjusted for asbestos exposure were higher for every benign pleural disease and asbestosis than the adjusted risks. These findings are consistent with the notion that the presence of pleural disease is dose related and are simply a surrogate for exposure in cohorts where exposure has not been measured.

The estimates of asbestos exposure in the Wittenoom cohorts have been criticised for being underestimated. However, dose-response relations have previously been validated internally within the cohort ${ }^{27} 28$ and fibre content of lung tissue has also been shown to correlate with dose estimates based on the exposure measurements. ${ }^{29}$ It is possible that the underestimation of asbestos exposure was greater in those with heavier exposure. This may explain why asbestosis and diffuse pleural thickening are better predictors of peritoneal mesothelioma than pleural mesothelioma.

Participants in the cancer prevention programme were younger and had heavier asbestos exposure than those former Wittenoom workers who were invited to participate in the study but who declined to do so. ${ }^{16}$ The mean (range) duration of crocidolite exposure (days) was 381 (1-6205) for the participants and 276 (1-3862) for non-participants.
Similarly, the average intensity of exposure (fibres/ml) was 24 (1-130) for participants and 23 (1-130) for nonparticipants. These differences may contribute to a possible bias in the exposure-response relation given that the asbestos exposure underestimates may have been greater in those with heavier asbestos exposure.

In this cohort of former Wittenoom workers and residents, the presence of asbestosis, blunt or obliterated costophrenic angle, diffuse pleural thickening, or pleural calcification were not associated with an increased risk of malignant pleural mesothelioma after allowing for the degree of asbestos exposure based on quantitative data. In contrast persons with diffuse pleural thickening or asbestosis have an increased risk of peritoneal mesothelioma even after adjusting for the estimates of asbestos exposure. This observation may be related to the biology of the disease process.

\section{ACKNOWLEDGEMENTS}

We acknowledge Jan Sleith, Vitamin A cancer prevention programme staff, Lynne Defrenne, Meralyn Pearce, Leanne Reid, Naomi Hammond, The Jem Foundation, National Health and Medical Research Council, Sarah de Klerk, and Zeb Jamrozik.

\section{Authors' affiliations}

A Reid, G Ambrosini, N Olsen, N de Klerk, A W Musk, School of Population Health, University of Western Australia, Australia S C Pang, Perth Chest Clinic, Health Department of Western Australia, Australia

Competing interests: none

\section{REFERENCES}

1 Hillerdal G. Pleural plaques and risk for bronchial carcinoma and mesothelioma. A prospective study. Chest 1994;105:144-50.

2 Bianchi C, Brollo A, Ramani L, et al. Pleural plaques as risk indicators for malignant pleural mesothelioma: a necropsy-based study. Am J Ind Med 1997;32:445-9.

3 Karjalainen A, Pukkala E, Kauppinen T, et al. Incidence of cancer among Finnish patients with asbestos-related pulmonary or pleural fibrosis. Cancer Causes Control 1999;10:51-7.

4 Koskinen K, Pukkala E, Martikainen R, et al. Different measures of asbestos exposure in estimating risk of lung cancer and mesothelioma among construction workers. J Occup Environ Med 2002;44:1190-6.

5 Armstrong BK, de Klerk NH, Musk AW, et al. Mortality in miners and millers of crocidolite in Western Australia. Br J Ind Med 1988;45:5-13.

6 Musk AW, de Klerk NH, Eccles JL, et al. Wittenoom, Western Australia: a modern industrial disaster. Am J Ind Med 1992;21:735-47.

7 Hansen J, de Klerk NH, Eccles JL, et al. Malignant mesothelioma after environmental exposure to blue asbestos. Int J Cancer 1993;54:578-81.

8 de Klerk NH, Musk AW, Armstrong BK, et al. Diseases in miners and millers of crocidolite from Wittenoom, Western Australia: a further follow-up to December 1986. Ann Occup Hyg 1994;38:S647-55.

9 Hansen J, de Klerk NH, Musk AW, et al. Mesothelioma after environmental crocidolite exposure. Ann Occup Hyg 1997;41:189-93.

10 Musk AW, de Klerk NH, Ambrosini GL, et al. Vitamin A and cancer prevention. I: Observations in workers previously exposed to asbestos at Wittenoom, Western Australia, Int J Cancer 1998;75:335-61

11 Hansen J, de Klerk N, Musk A, et al. Individual exposure levels in people environmentally exposed to crocidolite. Appl Occup Environ Hyg 1997; 12:485-90.

12 Hansen J, de Klerk NH, Musk AW, et al. Environmental exposure to crocidolite and mesothelioma: exposure-response relationships. Am J Respir Crit Care Med 1998;157:69-75.

13 de Klerk NH, Musk AW, Williams V, et al. Comparison of measures of exposure to asbestos in former crocidolite workers from Wittenoom Gorge, W. Australia. Am J Ind Med 1996;30:579-87

14 de Klerk NH, Armstrong BK, Musk AW, et al. Predictions of future cases of asbestos-related disease among former miners and millers of crocidolite in Western Australia. Med J Aust 1989;151:616-20.

15 Berry G. Prediction of mesothelioma, lung cancer, and asbestosis in former Wittenoom asbestos workers. Br J Ind Med 1991;48:793-802.

16 de Klerk NH, Musk AW, Ambrosini GL, et al. Vitamin A and cancer prevention. II: Comparison of the effects of retinol and beta-carotene. Int J Cancer 1998;75:362-7.

17 Omenn G, Goodman G, Thornquist M, et al. Effects of a combination of beta carotene and vitamin $A$ on lung cancer and cardiovascular disease. N Engl J Med 1996;334:1150-5.

18 Albanes D, Heinonen OP, Huttunen JK, et al. Effects of alpha-tocopherol and beta-carotene supplements on cancer incidence in the alpha-tocopherol betacarotene cancer prevention study. Am J Clin Nutr 1995;62:S1427-30. 
19 ILO. Guidelines for the use of ILO international classification of radiographs of pneumoconioses. Geneva: International Labour Office, 1980.

20 Stata Statistical Software. Release 8.0 version. College Station, TX: Stata Corporation, 2003.

21 Jarvholm B, Sanden A. Lung cancer and mesothelioma in the pleura and peritoneum among Swedish insulation workers. Occup Environ Med 1998;55:766-70.

22 Newhouse ML, Berry G. Patterns of mortality in asbestos factory workers in London. Ann N Y Acad Sci 1979:330:53-60.

23 Browne K, Smither WJ. Asbestos-related mesothelioma: factors discriminating between pleural and peritoneal sites. Br J Ind Med 1983;40:145-52.

24 Leigh J, Rogers AJ, Ferguson DA, et al. Lung asbestos fiber content and mesothelioma cell type, site, and survival. Cancer 1991;68:135-41.
25 Berry G, de Klerk N, Reid A, et al. Malignant pleural and peritoneal mesotheliomas in former miners and millers of crocidolite at Wittenoom, Western Australia. Occup Environ Med 2004;61:1-3.

26 Cvitanovic S, Znaor L, Konsa T, et al. Malignant and non-malignant asbestosrelated pleural and lung disease: 10-year follow-up study. Croat Med J 2003;44:618-25

27 Rogers A, Major $G$. The quantitative risks of mesothelioma and lung cancer in relation to asbestos exposure: the Wittenoom data. Ann Occup Hyg 2002;46:127-8.

28 Musk AW, de Klerk NH. Reply. Ann Occup Hyg 2002;46: 128-9.

29 Williams V, de Klerk NH, Whitaker $\mathrm{D}$, et al. Asbestos bodies in lung tissue following exposure to crocidolite. Am J Ind Med 1995;28:489-95.

\section{$\mathrm{ECHO}$}

\section{Smoking at work costs Taiwan \$US1bn}

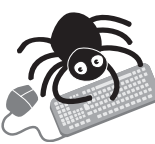

Please visit the Occupational and

Environmental Medicine website [www. occenvmed. com] for a link to the full text of this article.
D esearchers in Taiwan are advocating a total ban on smoking at work to avoid an estimated \$USIbn loss in productivity- $0.36 \%$ of its total gross domestic product in 2000. Reducing smoking in the working population should be a cost effective way to raise national productivity, they believe.

The total estimate of $1032 \mathrm{~m}$ encompassed $\$ 184 \mathrm{~m} /$ year for excess sick days among smokers: 1.06/year-cost $\$ 178 \mathrm{~m}$ - for men and $1.21 /$ year- $\$ 6 \mathrm{~m}$-for women. Estimated costs of $\$ 81 \mathrm{~lm}$ resulted from sickness absence in non-smokers owing to effects of environmental tobacco smoke and $\$ 34 \mathrm{~m}$ from occupational injuries. A staggering $\$ 733 \mathrm{~m}$ was the direct result of time lost in smoking breaks: on average 72 hours/year for men and 48 hours/year for women.

How close these are to true costs is open to question, the researchers concede, as the human capital method they used to calculate lost productivity, in which value equates to wage/salary, can overestimate costs.

The calculations rely on data from previous studies, but the contribution of potential confounders cannot be assessed. A possible candidate could be an effect of drug and alcohol use in greater sickness absence among smokers, the researchers say, and education, socioeconomic state, diet, and occupational factors may operate.

Nevertheless, smoking probably has a big impact on productivity, given that two million of Taiwan's four million smokers are in the working population, and it is surprising that more financial costings have not been published. Smoking bans exist in public places in Taiwan, but companies operate their own smoking policies.

A Tsai SP, et al. Tobacco Control 2005; 14:i33-i44. 